\title{
Hematopoietic cell differentiation from embryonic and induced pluripotent stem cells
}

Wai Feng Lim ${ }^{1,2^{* \dagger}}$, Tomoko Inoue-Yokoo ${ }^{1,3+}$, Keai Sinn $\operatorname{Tan}^{1,2}$, Mei I Lai ${ }^{2}$ and Daisuke Sugiyama ${ }^{*^{*}}$

\begin{abstract}
Pluripotent stem cells, both embryonic stem cells and induced pluripotent stem cells, are undifferentiated cells that can self-renew and potentially differentiate into all hematopoietic lineages, such as hematopoietic stem cells (HSCs), hematopoietic progenitor cells and mature hematopoietic cells in the presence of a suitable culture system. Establishment of pluripotent stem cells provides a comprehensive model to study early hematopoietic development and has emerged as a powerful research tool to explore regenerative medicine. Nowadays, HSC transplantation and hematopoietic cell transfusion have successfully cured some patients, especially in malignant hematological diseases. Owing to a shortage of donors and a limited number of the cells, hematopoietic cell induction from pluripotent stem cells has been regarded as an alternative source of HSCs and mature hematopoietic cells for intended therapeutic purposes. Pluripotent stem cells are therefore extensively utilized to facilitate better understanding in hematopoietic development by recapitulating embryonic development in vivo, in which efficient strategies can be easily designed and deployed for the generation of hematopoietic lineages in vitro. We hereby review the current progress of hematopoietic cell induction from embryonic stem/induced pluripotent stem cells.
\end{abstract}

\section{Introduction}

Hematopoietic stem cells (HSCs) lay the foundation of hematopoiesis to generate all functional hematopoietic lineages, including erythrocytes, leukocytes (neutrophils, basophils, eosinophils, lymphocytes, monocytes and macrophages) and platelets [1]. Perturbations in the hematopoietic system have been reported to cause numerous diseases such as anemia, leukemia, lymphomas and thrombocytopenia. Currently, HSC transplantation and hematopoietic cell transfusion are useful treatments for some hematological diseases, such as thalassemia and leukemia. However, some conventional sources of HSCs - such as cord blood, bone marrow and peripheral blood - are limited in usage, owing to the limited number of transplantable cells as well as inefficient strategies

\footnotetext{
*Correspondence: limwaifeng85@gmail.com; ds-mons@yb3.so-net.ne.jp ${ }^{\dagger}$ Equal contributors

${ }^{1}$ Department of Advanced Medical Initiatives, Division of Hematopoietic Stem Cells, Advanced Medical Initiatives, Faculty of Medical Sciences, Kyushu University, Station for Collaborative Research 1, 4F, 3-1-1 Maidashi, Higashi-Ku, Fukuoka 812-8582, Japan

${ }^{2}$ Department of Pathology, Faculty of Medicine and Health Sciences, Universiti Putra Malaysia, 43400 UPM, Serdang, Selangor Darul Ehsan, Malaysia

Full list of author information is available at the end of the article
}

for expanding those cells. Additionally, problems such as shortage of human leukocyte antigen-matched donors, adverse effects from graft-versus-host disease, viral contamination and immunoreactions impede the utility of readily available HSCs. The use of alternative sources for these cells will therefore be a great advantage for regenerative medicine.

Pluripotent stem cells are one of the potential sources for HSCs and the in vitro model for further elucidating the regulatory mechanisms underlying embryonic hematopoietic development. Embryonic stem (ES) cells are pluripotent cells established from the inner cell mass of blastocyst-stage embryos, in both mouse and human $[2,3]$, and are capable of giving rise to three germ layers after directed differentiation in culture [3,4]. However, manipulation of human ES cells raises some ethical issues and immunoreactions. Induced pluripotent stem (iPS) cell technology has made a groundbreaking discovery to circumvent the problems of ethical and practical issues in using ES cells [5]. It is of great importance to develop efficient and controllable induction strategies to drive hematopoietic differentiation from ES/iPS cells in culture prior to the realization of pluripotent cell-derived therapies. To review current progress of 


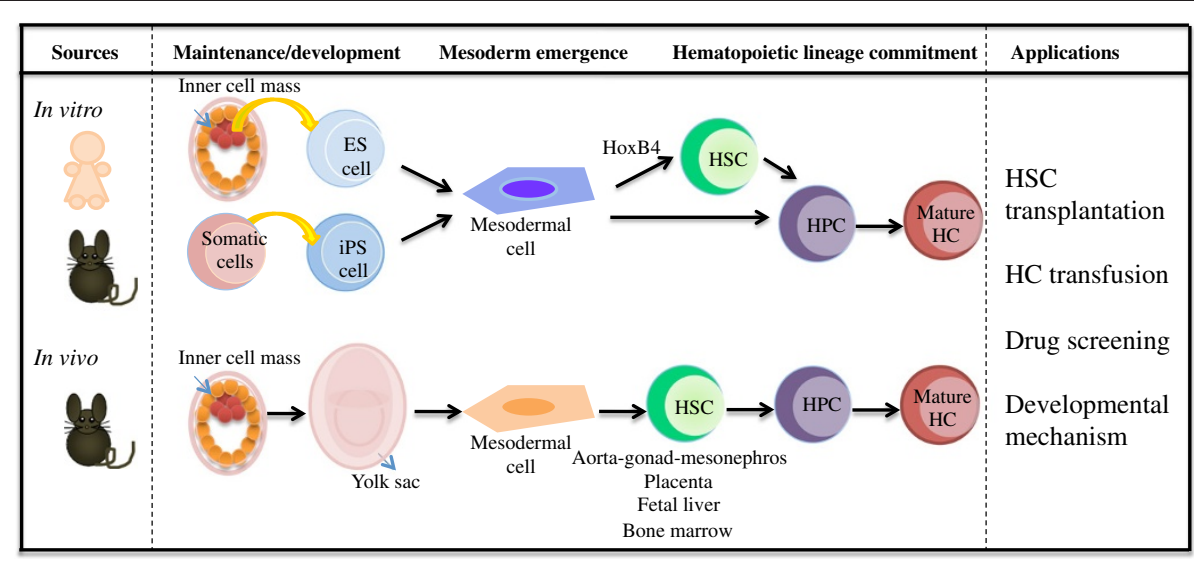

Figure 1 Schematic representations of hematopoietic development from in vivo and in vitro models. Both human and mouse in vitro models have been established for hematopoietic differentiation in a defined culture system from embryonic stem (ES) and adult cell-derived induced pluripotent stem (iPS) cells. For the in vivo model, the mouse inner cell mass undergoes differentiation, later forming the yolk sac, which generates mesodermal cells and induces hematopoietic stem cells (HSCs), hematopoietic progenitor cells (HPCs) and mature hematopoietic cells (HCs). Successfully generated HSCs from both in vitro and in vivo models might be applied to HSC transplantation for hematopoietic disorders. Further differentiation of HSC in a cytokine-defined culture system produces hematopoietic cells for hematopoietic cell transfusion. Thorough understanding of molecular mechanism on these models will be beneficial for both drug screening as well as the mechanism of hematopoiesis development.

differentiation protocol from ES/iPS cells, we first summarize the knowledge of hematopoietic development during early mouse hematopoiesis followed by the manipulation of ES/iPS cells in hematopoietic cell induction (Figure 1).

\section{Embryonic hematopoiesis}

Studies of hematopoietic development during embryogenesis in vivo are important to gain insight into its underlying mechanisms, whereby accumulated knowledge will facilitate the induction of HSCs, hematopoietic progenitor cells (HPCs) and mature hematopoietic cells from pluripotent stem cells in culture. In mouse blastocyst, the inner cell mass at 3.5 days post coitum (dpc) comprises a population of cells - which can give rise to a derivative of three germ layers (endoderm, mesoderm and ectoderm) - that eventually develop into both intraembryonic and extraembryonic tissues as embryo develops [6]. The hematopoietic system that derives from the mesodermal germ layer can be classified into two waves. The first hematopoiesis (primitive hematopoiesis) begins to develop primitive erythroid and macrophage progenitors in the yolk sac (YS) blood islands at $7.0 \mathrm{dpc}$ [7]. Para-aortic splanchnopleural regions that will develop into aorta-gonad-mesonephros (AGM) already possess hematopoietic precursors beginning at $8.5 \mathrm{dpc}$ [8]. Before the establishment of circulation $(8.0 \mathrm{dpc})$, both YS and para-aortic splanchnopleural-derived mesodermal cells acquire HSC activity after co-culturing with AGMderived stromal cells [9]. After circulation commences, $\mathrm{CD} 4^{+} \mathrm{c}-\mathrm{Kit}^{+}$cells derived from both YS and para-aortic splanchnopleura at $9.0 \mathrm{dpc}$ were able to reconstitute the hematopoietic system in newborn recipient pups, but not in adult recipient mice [10]. These findings demonstrate that both YS and para-aortic splanchnopleura possess HSC potential that can contribute to definitive hematopoiesis under a favorable microenvironment.

The first definitive HSCs that can reconstitute the adult hematopoietic system appear in the AGM region at $10.5 \mathrm{dpc}$ followed by the YS, placenta and liver, spanning from 11.0 to $11.5 \mathrm{dpc}$ [11-13]. YS cells expressing Runx 1 at $7.5 \mathrm{dpc}$ progressed into fetal lymphoid progenitors at $16.5 \mathrm{dpc}$ in both fetal liver and thymus as well as adult HSCs in 9-month-old to 12-month-old mouse bone marrow [14]. In view of these results, both the YS and the AGM region contribute to HSC generation. However the extent of their contribution still remains unclear. To address this issue, YS-YS chimeric embryos were generated before blood circulation at $8.25 \mathrm{dpc}$, where no B-cell activity was detected, which is relevant to HSC activity in the early mouse embryo. As the chimeric embryos develop into $11.0 \mathrm{dpc}$ equivalent in whole embryo culture, the grafted YS cells contributed to B-cell activity in the AGM region, but with low frequency [15]. This observation implies that the main source of HSCs is derived from the AGM region.

In addition to the YS and the AGM region, the placenta is another site for HSC generation. The placenta exchanges oxygen and nutrient between mother and fetus, and is formed around $9.0 \mathrm{dpc}$ after fusion of chorion and allantois. A fluorescent-labeled allantois region at $8.25 \mathrm{dpc}$ could be detected in the hematopoietic cell cluster after 42 hours of whole embryo culture, suggesting that allantois alone possesses HSC potential 
and also proposing that the placenta is likely to be an ixndependent site of HSC generation, regardless of cells circulating from other hematopoietic organs [16]. Taken together, the YS, AGM region and placenta contribute to HSC generation prior to the HSC expansion in the fetal liver .

\section{Gene and protein markers for mesodermal and hematopoietic lineages}

During early embryonic development, Brachyury that is indispensable for mesodermal formation expresses transiently [17]. Subsequently tyrosine kinase Flk1 for bloodisland formation and vasculogenesis expresses in hemangioblasts, which is the common embryonic endothelial and hematopoietic precursor [18].

Transcription factors characterized to be involved in the hematopoietic lineages are shown below. In the transition of mesodermal to hematopoietic lineages, $\mathrm{Scl}$ is indispensable for the development of all hematopoietic lineages, in which a homozygous mutant $\mathrm{Scl}^{-1-}$ model showed undetectable hematopoietic lineages in both in vivo and in vitro studies [19]. Runx1 plays an important role in governing definitive hematopoiesis but not primitive hematopoiesis through the observation of blast colony-forming cells, which are both hematopoietic and endothelial cell precursors from ES cells and equivalent of hemangioblast, using a Runx $1^{-/-}$ES cell culture model [20]. The GATA family of transcription factors, especially GATA-1 and GATA-2, are differentially regulated at multiple steps from the early development of hemangioblast to hematopoietic commitment [21].

Surface markers of hematopoietic lineages are briefly described. Cells expressing endothelial markers, such as CD34, PECAM-1 (CD31) and VE-cadherin, are closely associated with both hematopoietic and endothelial cell commitment [22]. Expression of CD41 initiates the primitive and definitive hematopoiesis, whereas HPCs are highly dependent on c-Kit expression [23]. Additionally, CD34 as a marker for HSCs and CD45 as a marker for pan-leukocyte and/or maturation of HSCs are utilized respectively $[24,25]$.

\section{Differentiation of embryonic stem/induced pluripotent stem cells and hematopoietic cell induction}

Mouse ES/iPS cells can be maintained and propagated indefinitely on a layer of mitotically inactivated mouse embryonic fibroblasts (MEFs) and/or leukemia inhibitory factor in culture. On the contrary, human ES cells achieve an undifferentiated state on a layer of MEFs and/or basic fibroblast growth factor. After removal of leukemia inhibitory factor and basic fibroblast growth factor, these ES cells can differentiate into any kind of cell depending on appropriate culture conditions. One of the ultimate goals of in vitro differentiation of ES/iPS cells is to generate HSCs with the acquisition of longterm reconstitution capacity.

By recapitulating mouse embryogenesis, in vitro differentiation of ES/iPS cells toward hematopoietic development has been technically approached: through formation of a cystic-like structure that exhibits three germ layers that are able to generate mesodermal cells (embryoid body (EB) formation); through feeder cell co-culture that can provide ES/iPS cells an intimate cell contact with secreting factor(s) that promote cell proliferation and differentiation (feeder cell co-culture); and through an extracellular matrix-coated dish that supports differentiation of ES/iPS cells (Figure 2).

\section{Embryoid body formation}

EBs are three-dimensional cell aggregates formed in suspension culture and they mimic the spatial organization of the embryo through enhancing cell-cell interactions to form three germ layers $[3,4]$. There are a number of approaches to EB formation, such as methylcellulose or suspension culture medium either using a bacterialgrade dish, a methylcellulose-coated plate, a low-adherent micro-well plate or the hanging drops method. To specifically induce a hematopoietic lineage, single-cell suspension of EBs are directed into methylcellulose culture medium that functions to support hematopoietic development in the presence of hematopoietic cytokines, such as stem cell factor (SCF), granulocyte colony-stimulating factor (CSF), macrophage CSF, granulocyte-macrophage CSF, erythropoietin (Epo) and interleukins (ILs) such as IL-1, IL-3, IL-4 and IL-6 [26]. In the absence of cytokines in culture, EB cells themselves reportedly possess the capability to secrete proteins having macrophage CSF, IL-3 and Epo activity in order to support the early development of erythroid and macrophage precursors [27].

Using mouse ES cells, 75\% of blast colonies were generated from EBs of methylcellulose culture consisting of bipotential precursors (hematopoietic and endothelial cells) as blast colony-forming cells at day 2.5 , and then decreased at day $4(<15 \%)$ [28]. In mouse ES cells with GFP targeted to the Brachyury, EB formation at day 2.5 in suspension culture gave rise to $\mathrm{GFP}^{-} \mathrm{Flk1}^{-}, \mathrm{GFP}^{+} \mathrm{Flk} 1^{-}$ and $\mathrm{GFP}^{+} \mathrm{Flk} 1^{+}$distinct populations, which are comparable with the developmental progression ranging from pre-mesoderm to pre-hemangioblast mesoderm to the hemangioblast, respectively [29].

EBs derived from human ES cells formed three embryonic germ layers that can be identified using the following markers: $\zeta$-globin, neurofilament $68 \mathrm{Kd}$ and $\alpha$-fetoprotein [30]. By differentiating human ES cells through EBs at day 3.0 to 4.0, blast colony-forming cells were generated in liquid culture and expressed FLK1, BRACHYURY and SCL genes [31]. Differentiation of 


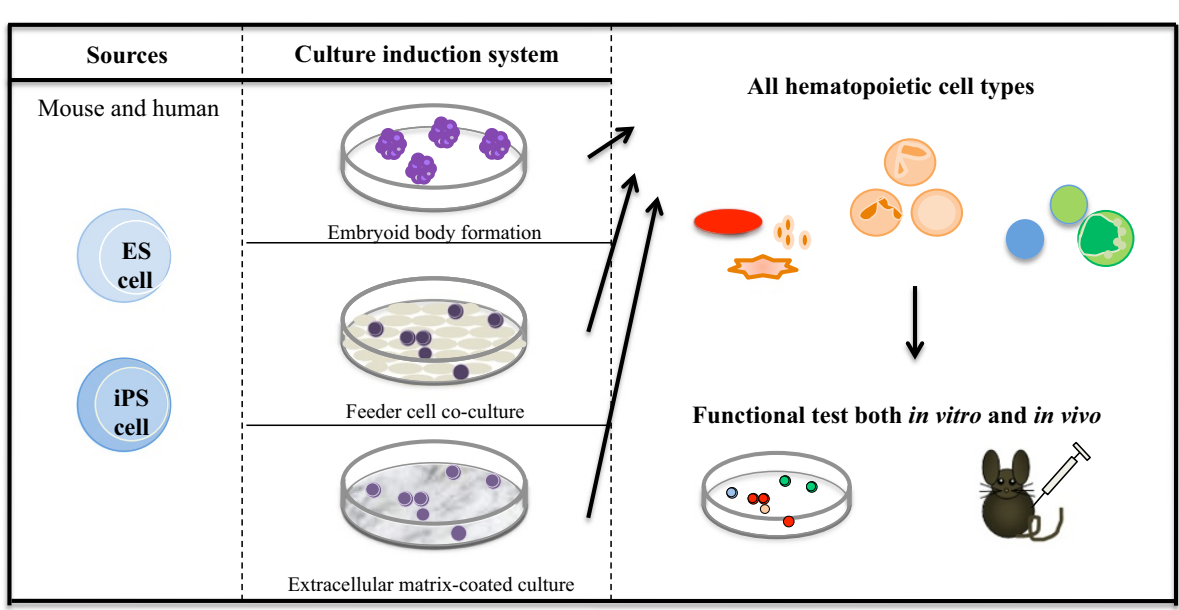

Figure 2 Schematic representations of induction systems and criteria for successful hematopoietic development. Both mouse and human embryonic stem (ES)/induced pluripotent stem (iPS) cells can be differentiated into hematopoietic cells (HCs) from mesodermal cells with three approaches: embryoid body formation, feeder cell co-culture and extracellular matrix-coated culture. Hematopoietic stem cells and differentiated HCs must be tested and screened both in vitro and in vivo before being applied to patients.

human iPS cells throughout a 21-day EB formation demonstrated a sequential gene expression from BRACHYURY (mesoderm) to GATA-2 and SCL (hematopoietic commitment), followed by the emergence of $\mathrm{CD} 34^{+} \mathrm{CD} 45^{+}$cells that denote hematopoietic lineages [32].

To improve the efficiency of EB formation using human ES cells, the modified spin-EB technique has been developed - in which a defined number of human ES cells are aggregated by centrifugation in low-attachment 96-well plates, and which could reproduce the hematopoietic differentiation potential with more than $90 \%$ of the wells able to form hematopoietic cells. This spin-EB method efficiently accelerates hematopoietic differentiation and approximately 500 hematopoietic progenitors are induced from single ES cells [33]. Human iPS cells also differentiate into hematopoietic cells by the spin-EB method. $\mathrm{CD}_{4}{ }^{+}$cells derived from them are $\mathrm{CD}^{+} 5^{+}$(27 to $64 \%$ ) and $\mathrm{CD}_{4} 3^{+}$(36 to $60 \%$ ) after 13 to 17 days of culture [34].

\section{Feeder cell co-culture}

Co-culture is a method of culturing a layer of feeder cells together with ES/iPS cells to give support to the growing cells (germ layer cells) towards development of hematopoietic lineages in appropriate culture medium. A well-known feeder cell layer, OP9 stromal cells are derived from newborn bone marrow of the mouse calvaria model, which reveals osteopetrosis due to lack of macrophage CSF [35]. In addition to OP9 co-cultures, stromal cells from the AGM region can be used to support hematopoiesis of both mouse and human ES cells in the culture system, suggesting that factors such as cytokines are secreted to regulate the early stem cell development and hematopoietic differentiation in vitro [36].
In mouse ES cells, the use of OP9 stromal cells could promote lymphohematopoietic differentiation by minimizing preferential differentiation towards monocytemacrophage lineages [37]. AGM stromal cell co-cultures with mouse ES cells could induce $\mathrm{CD} 45^{+}$hematopoietic cells, including cell differentiation from both Mac- ${ }^{+}$ myeloid cells and $B 220^{+}$B cells, suggesting that AGM stromal cell lines support hematopoietic differentiation. To improve the efficiency of hematopoietic differentiation, a two-step co-culture system was designed, first by co-culturing of mouse ES cells with OP9 cells followed by AGM stromal cells at defined time points. Approximately $90.6 \%$ of $\mathrm{CD} 45^{+}$hematopoietic cells (23.6\% in the OP9 system), $87 \%$ of Mac- $1^{+}$cells (16\% in the OP9 system) and $19.1 \%$ of $\mathrm{c}-\mathrm{Kit}^{+}$cells $(43 \%$ in the OP9 system) could be detected using this system [36]. Using a colony-forming assay, Krassowska and colleagues showed that ES cell-derived mesodermal cells could stimulate HPC production with 3.5-fold efficiency in primary AGM region co-cultures as compared with those derived from feeder-free culture. They also cocultured differentiating ES cells on the dorsal aorta and mesenchyme-derived, urogenital ridge-derived and fetal liver-derived stromal cell lines that had previously been reported to support BM-derived HSCs [38]. The timecourse of ES/iPS cell differentiation towards hematopoietic cells does not synchronize with regular hematopoietic differentiation, implying that hematopoietic differentiation does not occur via HSCs. In OP9 cell co-culture, mouse iPS cells initially formed Brachyury-expressing mesodermal cells and later co-cultured again onto fresh OP9 cells supplemented with hematopoietic cocktails were induced to form hematopoietic lineages, including erythroid and myeloid lineage cells but not lymphoid lineage cells [39]. 
Human ES/iPS cells co-cultured with OP9 cells generated HPCs defined by $\mathrm{CD} 34^{+} \mathrm{CD} 43^{+}$expression and evaluated by the clonogenic progenitor cell assay [40]. Using a co-culture system with mouse fetal liver-derived stromal cells, human ES cells could generate the erythroid progenitors as determined by colony-forming cells, followed by enucleated erythrocytes with oxygen-carrying capacity [41]. To examine the properties among stromal cells, primary cells and cell lines derived from the mouse AGM region and fetal liver were compared in supporting hematopoietic differentiation from human ES cells. Eighteen days after co-culturing, primary cells derived from the AGM region exhibited the highest number of both $\mathrm{CD} 4^{+}$and $\mathrm{CD} 45^{+}$cells among the cells, suggesting that cell lines probably lose their ability to support during the passages [42].

\section{Extracellular matrix-coated dish}

Dishes coated with extracellular matrixes, such as collagen and fibronectin, are used as monolayer cultures to differentiate ES/iPS cells. In mouse ES cells, the use of collagen IV-coated dishes directs the generation of $\mathrm{E}$ cadherin $^{-}$Flk $1^{+} \mathrm{VE}$-cadherin ${ }^{-}$-expressing mesodermal cells and further accelerate differentiation into hemangioblast $\left(\right.$ VE-cadherin $\left.{ }^{+} \mathrm{Flk} 1^{+} \mathrm{CD} 45^{-}\right)$, HPCs $\left(\mathrm{c}-\mathrm{Kit}^{+} \mathrm{CD} 45^{+}\right)$and mature hematopoietic cells $\left(\mathrm{c}-\mathrm{Kit}^{-} \mathrm{CD} 45^{+}\right.$or Ter119 ${ }^{+}$) [43].

In human ES/iPS cells, matrixes such as human fibronectin, human collagen IV and mouse collagen IV are utilized to generate hematopoietic progenitors $\left(\mathrm{CD} 43^{+} \mathrm{CD} 34^{+}\right)$, which could give rise to several lineages of differentiated blood cells including erythroid cells $\left(\mathrm{CD} 71^{+} \mathrm{CD} 235 \mathrm{a}^{+}\right)$, megakaryocytes $\left(\mathrm{CD} 41 \mathrm{a}^{+} \mathrm{CD} 42 \mathrm{~b}^{+}\right)$, neutrophils $\left(\mathrm{CD} 15^{+} \mathrm{CD} 66 \mathrm{~b}^{+}\right)$, macrophages $\left(\mathrm{CD} 14^{+} \mathrm{CD} 68^{+}\right)$ and dendritic cells (HLA-DR ${ }^{+} \mathrm{CD}^{2} \mathrm{a}^{+}$) phenotypically [44]. Human ES/iPS cells could differentiate into mesodermal cells in the presence of the major matrix components such as laminin, collagen I, entactin and heparin-sulfate proteoglycan as well as growth factors and several other undefined compounds. These mesodermal cells were able to induce hematopoietic cells after substitution with hematopoietic cocktail culture medium [45].

These studies suggested that monolayer culture system could commit hematopoietic potential in differentiating ES/iPS cells. Combination of this system with xenogeneicfree culture has been widely considered a more suitable approach for future clinical applications.

\section{Embryonic stem/induced pluripotent stem cell-derived hematopoietic lineages}

As mechanisms of hematopoietic development in both mouse and human are being established, manipulation of ES/iPS cells for hematopoietic differentiation is also improving. ES/iPS cells possess embryonic natures and are likely to be differentiated into primitive hematopoietic cells.
Exogenous cytokines, feeder cells and extracellular matrixcoated dishes enable ES/iPS cells to differentiate into definitive hematopoietic cells in addition to primitive types. In the following section, induction of hematopoietic cell types from both mouse and human ES/iPS cells is described (Figure 3).

\section{Hematopoietic stem cells and hematopoietic progenitor cells}

HSCs are the cells that possess self-renewing capacity to maintain the stem cell pool and multipotency to differentiate into all lineages of mature hematopoietic cells, while HPCs do not self-renew and their differentiation capacity is limited only to certain types of cells. HSCs/ HPCs can be defined by the surface marker expressions, which enables us to investigate the molecular mechanisms underlying HSC/HPC development. Mousederived HSCs/HPCs are commonly defined by lineage marker ( $\mathrm{Lin}^{-}$, a cocktail of lineage markers including B220, Ter119, Mac-1, Gr-1, CD3, CD4 and CD8), stem cell antigen $\left(\mathrm{Sca}-1^{+}\right.$, a putative marker of stem and progenitor cells) [46], c- $\mathrm{Kit}^{+}$(a receptor for SCF) [47], $\mathrm{CD}^{\text {low }}{ }^{\text {[48] }}$ and $\mathrm{Tie}^{+}{ }^{+}$(a tyrosine kinase receptor expressed in endothelial and hematopoietic cells) [49]. However, unlike in mouse, CD34 is the representative marker for human HSCs [50].

In mouse ES cells, after co-culturing them with the bone marrow stromal cell line with a combination of IL3, IL-6, fetal calf serum and cell-free supernatants of fetal liver stromal cell line culture, the $\mathrm{PgP}-1^{+}(\mathrm{CD} 44$, phagocytic glycoprotein-1) $\mathrm{Lin}^{-}$cells (B220-Mac-1 ${ }^{-}$ JORO75 $^{-}$Ter119- (JORO75 is a marker of T-cell progenitors)) are generated and transplanted to repopulate the lymphoid, myeloid and erythroid lineages of primary adult irradiated mice 15 to 18 weeks posttransplantation. The PgP- $1^{+} \mathrm{Lin}^{-}$cells also possess selfrenewal potential as examined in secondary adult irradiated mice after 16 to 20 weeks post-transplantation [51].

Primitive HPCs were generated from EB-derived mouse ES cells and injected into lethally irradiated adult mice to reconstitute the hematopoiesis system, showing a survival rate of more than 3 weeks and subsequently lymphoid and myeloid engraftment from CD $45^{+}$ESderived cells was detected 12 weeks post-transplantation [52]. Another group demonstrated the acquisition of long-term multilineage capacity in lethally irradiated mice after injection with $\mathrm{c}-\mathrm{Kit}^{+} \mathrm{CD} 45^{+} \mathrm{HSCs}$, which was derived from mouse ES cells in methylcellulose culture supplemented with SCF, IL-3, IL-6 and fetal bovine serum [53]. However, the reproducibility of these results still remains elusive, suggesting that those successful attempts were highly dependent on the individual culture condition setup as well as the cellular phenotype of HSCs/HPCs that are being investigated. 


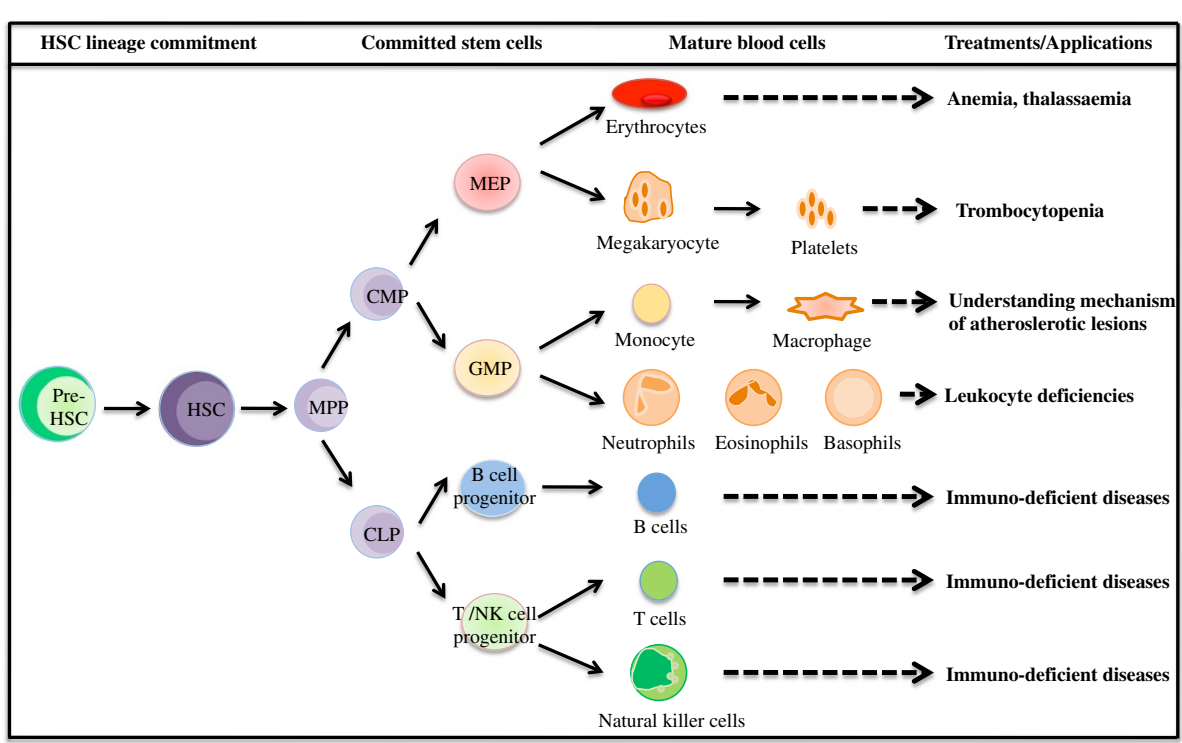

Figure 3 Schematic representations of each hematopoietic cell lineage with respect to their applications and disease-treatment potentials. After pre-hematopoietic stem cells (HSCs) commit to mature HSCs, multipotent progenitor (MPP) cells are generated with the potential to further differentiate into two major lineages: common myeloid progenitor (CMP) and common lymphoid progenitor (CLP). In myeloid lineage, CMP will further divide into megakaryocyte-erythroid progenitor (MEP) and granulocyte/monocyte progenitor (GMP), finally committing to mature blood cells comprising of erythrocytes, megakaryocyte $\rightarrow$ platelets, monocyte $\rightarrow$ macrophages and granulocytes (neutrophils, eosinophils, basophils). In lymphoid lineage, CLP will further differentiate into B-cell and T-cell and natural killer (NK) cell progenitors, with a final commitment to mature B cells, T cells and NK cells. Each lineage serves as a powerful regenerative tool, including treatment for hemoglobinopathies (anemia, thalassemia), thrombocytopenia, leukocyte and immunodeficient-related diseases. This model might also clarify the molecular mechanism behind certain disorders, for example atherosclerotic lesions.

In addition, ectopic expression of certain genes into ES/iPS cells has been used to induce development of HSCs/HPCs in an in vitro system. HoxB4 (a homeobox transcription factor) was retrovirus-transduced into EBderived mouse ES cells followed by co-cultures in OP9 stromal cells to induce hematopoietic development. This has resulted in a population of definitive HSCs that could repopulate lymphoid and myeloid cell lineages in both primary and secondary transplanted irradiated adult mice [54]. On the other hand, Wang's group exploited the fact that ectopic expression of Cdx4 (a family of caudal-related homeobox-containing transcription factors) in mouse ES cells induced mesodermal specification together with increased HPC production. With this notion, they also observed the synergistic effect of HoxB4 and Cdx4 on HPC production after EB-derived ES cells grown on OP9 stromal cells, and those cultured cells could support the engraftment of all hematopoietic lineages in irradiated adult mice [55]. EB-derived mouse ES cells are able to generate $\mathrm{c}-\mathrm{Kit}^{+} \mathrm{CD} 41^{+} \mathrm{CD} 45^{-}$cells without HoxB4 regulation, but their ability to reconstitute adult hematopoiesis is only seen after those cells undergo maturation in OP9 co-cultures in the presence of HoxB4, which was measured by total chimerism 16 weeks post-transplantation of fractionated cocultured cells, such as $\mathrm{CD}_{4} 1^{+}$cells, c-Kit ${ }^{+}$cells, CD $34^{+}$ cells and $\mathrm{CD} 45^{-}$cells [56], suggesting that HoxB4 probably regulates HSC maturation through upregulating the CD34 surface marker expression.

Although the production of $\mathrm{HSCs} / \mathrm{HPCs}$ is possible using a HoxB4-expressing approach, problems such as an inhibitory effect on lymphoid cell differentiation due to long-term constitutive HoxB4 expression [54] as well as the risk of leukemogenesis in dogs and monkeys after transducing with HOXB4-expressing retroviral vector [57] have been reported. To alleviate these adverse effects, EB-derived $\mathrm{CD} 41^{+} \mathrm{c}-\mathrm{Kit}^{+}$cells derived from ES/iPS cells were transduced with adenoviral vector of human HOXB4 and then co-cultured on OP9 stromal cells together with hematopoietic cytokines (SCF, fmslike tyrosine kinase 3 receptor ligand (Flt-3 ligand), thrombopoietin, IL-3 and IL-6) and fetal bovine serum. Although human HOXB4 expression was transiently expressed (expression level decreased 6 days posttransduction), those transduced $\mathrm{CD} 41^{+} \mathrm{C}-\mathrm{Kit}^{+}$cells could proliferate up to 20 days with traceable $\mathrm{CD} 45^{+}, \mathrm{CD} 41^{+}$ and $\mathrm{Sca}-\mathrm{1}^{+}$, indicating the existence of immature hematopoietic cells with hematopoietic differentiation potential in a colony-forming assay [58]. However, whether these HPCs possess in vivo repopulation capacity remains an ongoing experiment. Nevertheless, with the use of iPS cell technologies, the humanized sickle 
cell anemic mouse has been successfully treated with the injection of HoxB4-induced mouse iPS cells (from tail tip fibroblast of this mouse), whereby the human sickle globin gene has been corrected through gene-specific targeting beforehand [59]. This finding suggests a valuable tool to approach human gene therapy.

In humans, ES cell-derived hematopoietic cells are engrafted successfully by direct femoral injection but not intravenous transplant (due to cell aggregation in response to rodent serum), enforce expression of HOXB4 in human ES-derived hematopoietic cells, but confer no effect in promoting repopulation capacity [60], suggesting that different mechanisms control HSC regulation between human and mouse ES cells. After human ES cell co-cultures with mouse fetal liver stromal cells, the derivation of multipotential HPCs from the cobblestone-like $\mathrm{CD}_{4} 4^{+}$cell populations displayed hematopoietic potential in a colony-forming assay [61]; however, the reconstitution capacity remains uninvestigated. On the other hand, Ji and colleagues used an OP9 stromal cell co-culture with human ES cells; although they found that OP9 stromal cells could prevent $\mathrm{CD} 45^{+} \mathrm{CD} 34^{+}$HPCs from apoptosis, those HPCs failed to engraft both adult and newborn NOD/SCID mice [62], suggesting that this model did not improve the repopulating capacity in HPCs, unlike in the mouse model. In OP9-free and serum-free culture conditions, ES/iPS cell differentiation on extracellular matrix-coated dishes could cultivate $\mathrm{HSCs} / \mathrm{HPCs}$, defined as $\mathrm{CD} 34^{+} \mathrm{CD} 45^{+}$ cells that could support myeloid, erythroid and megakaryocyte cell lineages in the presence of respective hematopoietic cytokines [45]. As an effort to overcome the shortage of HSC/HPC sources for transplantation, several attempts in generating them from ES/iPS cells have been reported; however, some of their in vivo reconstitution capacity still remains to be determined.

\section{Mature hematopoietic cells}

In this section, we review the current progress in lineage-restricted mature hematopoietic cells of pluripotent stem cell differentiation in culture.

\section{Erythrocytes}

Erythrocytes are differentiated sequentially from HSCs, BFU-E, CFU-E (erythroid progenitors) and later into erythroblasts and reticulocytes (immature erythrocytes) through a process known as erythropoiesis. Erythropoiesis involves a multistep regulation of cytokines such as Epo.

After EB formation of mouse ES cells, erythroid cells expressing $\beta H 1$ globin, Bmajor globin and Gata1 are generated in the presence of Epo and SCF in methylcellulose culture medium [63]. Co-culture of ES cells with OP9 stromal cells in the presence of Epo and IL-3 could generate erythroid cells that are characterized by Ter119 (glycophorin A-associated protein) [64]. By co-culturing of mouse iPS cells with OP9 stromal cells, c-Kit ${ }^{+} \mathrm{CD} 41^{+}$ HPCs were generated and transplanted into sickle cell anemia mice in which the anemic status was ameliorated, suggesting that HPCs derived from iPS cells differentiated into erythrocytes in vivo [59].

Human ES-derived erythrocytes principally express CD235a (glycophorin A) and both embryonic and fetal globins such as $\xi$-globin and $\gamma$-globin by EB formation and extracellular matrix culture [65]. Continuous coculture of human ES cells with fetal liver-derived stromal cells enables the induction of adult type $\beta$-globin, while suppressing $\xi$-globin expression [41]. On the other hand, Olivier and colleagues reported a three-step culture system to obtain large-scale production of erythroid cells, in which they co-cultured human ES cells with immortalized human liver cells, followed by culture of CD $34^{+}$cells with cytokines, and subsequently co-culturing with mouse bone marrow stromal cells. Consequently, ES-derived CD34 ${ }^{+}$cells could amplify the erythroid cells efficiently (5,000-fold to 10,000-fold in number), which are hemoglobinized and expressed embryonic-globin and fetalglobin, but not $\beta$-globin [66].

In human iPS cells, EB-derived $\mathrm{CD} 34^{+} \mathrm{CD} 45^{+} \mathrm{HPCs}$ established from patients with polycythemia vera could produce both CFU-E and CD235 $\mathrm{a}^{+} \mathrm{CD} 45^{-}$erythroid lineage cells in the presence of SCF, IL-3 and Epo [34]. Both human embryonic and fetal mesenchymal-reprogrammed iPS cells recapitulate early human erythropoiesis that are characterized by embryonic $\left(\zeta_{2} \varepsilon_{2}\right.$ and $\left.\alpha_{2} \varepsilon_{2}\right)$ and fetal $\left(\alpha_{2} \gamma_{2}\right)$ hemoglobin, by co-culturing iPS cells with human fetal liver-derived feeder layer, followed by liquid culture in the presence of IL-3, SCF, Epo, bone morphogenic protein 4 and insulin-like growth factor-1 [67].

\section{Granulocytes}

Granulocytes can be classified into neutrophils, basophils and eosinophils, which are differentiated from HPCs. Granulocyte differentiation antigen 1 (Gr-1) is commonly used as a marker for granulocytes. Both CD15 and CD11b are neutrophil and monocyte markers while CD16 is the mature neutrophil marker.

In mouse, $\mathrm{Gr}-1^{+}$neutrophils are generated from EBderived ES cells and after 4 to 20 days co-culture with OP9 cells in the presence of granulocyte CSF, granulocyte-macrophage CSF and IL-6. These neutrophils comprise granules of lactoferrin and gelatinase, and exhibit chemotactic responses and superoxide production [68].

In human ES cells, neutrophils expressing $\mathrm{CD} 15^{+}$, $\mathrm{CD}_{11 \mathrm{~b}^{+}}$and $\mathrm{CD} 16^{+}$exhibiting equivalent phenotype to those in peripheral blood are produced from the EBs after culture in OP9 cells with SCF, Flt-3 ligand, IL-6, IL-6 receptor, thrombopoietin, IL-3 and subsequently 
with granulocyte CSF, and exhibited oxidative burst function and phagocytic activity in vitro [69]. Culture of human iPS cells established from bone marrow mesenchymal stem cells (from a patient with X-linked chronic granulomatous disease) on OP9 stromal cells produced oxidase-deficient neutrophils. They were also successful in rescuing oxidase deficiency by gene modification using zinc finger nuclease-mediated safe harbor targeting [70]. This finding demonstrated that precise gene targeting might be applied to correct a disease-causing mutation in patient iPS cells.

\section{Lymphocytes}

Several kind of lymphocytes play important roles in regulating immune response, such as $\mathrm{T}$ lymphocytes/ $\mathrm{T}$ cells (CD3, CD4, CD8), B lymphocytes/B cells (CD10, CD19) and natural killer cells (CD56, CD94), which can be stimulated from mouse and human pluripotent stem cells.

In mice, mature $\mathrm{CD}^{+} \mathrm{T}$ cells expressing $\gamma \delta$ and $\alpha \beta$ T-cell receptors were generated from ES cells after co-culture on OP9-expressing Notch ligand, delta like 1 (OP9-DL1). Additionally, T-cell progenitors generated after stimulation by Flt-3 ligand and IL-7 were capable of reconstituting the T-cell compartments in sublethally irradiated $R a g 2^{-/-}$mice [71]. OP9-DL1 co-cultures with both iPS cell lines derived from murine splenic B cells and MEF also resulted in T-cell development with traceable CD44 and CD24 in addition to CD4 and CD8 markers, but are not committed to the $\mathrm{CD} 19^{+} \mathrm{B}$-cell lineage in the presence of Flt-3 ligand and IL-7 [72]. In the presence of Flt-3 ligand, IL-15, IL-6, IL-7 and SCF, co-cultures of mouse ES cells with OP9 stromal cells generated natural killer cells with CD94/NKG2 receptors to combat certain tumor cell lines and major histocompatibility complex (MHC) class I-deficient lymphoblasts [73].

Co-culturing of human ES cells with OP9 cells induced $\mathrm{CD} 34^{\text {high }} \mathrm{CD} 43^{\text {low }}$ cells, and subsequent culture of $\mathrm{CD} 34^{\text {high }} \mathrm{CD} 43^{\text {low }}$ cells in OP9-DL1 cells in the presence of Flt-3 ligand, IL-7 and SCF generate functional T cells that have a response to phytohemagglutinin stimulation [74]. After 10-day co-cultures of OP9 stromal cells with iPS cells derived from adult human dermal fibroblasts, $\mathrm{CD}_{4} 4^{+}$cells were harvested and subsequently cocultured on MS-5 stromal cells for another 21 days in the presence of SCF, Flt-3 ligand, IL-7 and IL-3, which were then capable of generating $\mathrm{CD} 45^{+} \mathrm{CD} 19^{+} \mathrm{CD} 10^{+}$ pre-B cells [75]. Additionally, using human pluripotent stem cells, Ni and colleagues demonstrated that the generation of $\mathrm{CD} 45^{+} \mathrm{CD} 56^{+}$and $\mathrm{CD} 117^{-} \mathrm{CD} 94^{+}$natural killer cells can inhibit HIV-1 infection [76], a possible potential to treat immunologic diseases in humans.

\section{Monocytes and macrophages}

Macrophages are differentiated from monocytes and function to regulate both innate and adaptive immunity to combat foreign particles including pathogens by stimulating the response of immune cells, such as lymphocytes. The putative surface markers for macrophages are CD11b (Mac-1), CD14 (ligand receptor of lipopolysaccharide), CD115 (colony-stimulating factor 1 receptor) and F4/80 (a highly glycosylated proteoglycan extracellular antigen).

In mice, after EB formation of CCEG2 and D3 ES cell lines, the generated HPCs drive the development of macrophage that expresses F4/80 marker in the presence of Epo, IL-1, IL-3 and macrophage CSF [27]. From bone marrow-derived iPS cells, macrophages were generated after co-culture with OP9 stromal cells and further induced differentiation in the presence of fetal calf serum and macrophage CSF. These iPS-derived macrophages showed similar expression of F4/80 and CD11b surface markers and phagocytic capacity with those bone marrow-derived macrophages [77].

In humans, co-culture of ES cells with S17 cells, a mouse bone marrow-derived stromal cell, were able to generate CD15-expressing macrophage progenitor cells [78]. After differentiating human ES cells by EB formation, monocytes and macrophages were induced in culture medium containing macrophage CSF and IL-3 [79]. EB formation of bone marrow mesenchymal stem cellreprogrammed iPS cells reportedly produce monocytemacrophage lineage cells after stimulation with cytokine cocktails including macrophage CSF and RANKL, evidenced by surface marker expression such as CD14, CD18, CD11b and CD115 [80].

\section{Megakaryocytes and platelets}

Platelets are particles fragmented from megakaryocytes that function in modulating hemostasis and vascular repair through cell aggregation and adhesion. CD41, also known as $\alpha$ IIb integrin, is reportedly expressed on megakaryocytes and platelets. This is a platelet glycoprotein relating to a complex of receptors such as fibronectin, fibrinogen, von Willebrand factor and thrombin that regulate platelet aggregation and attachment to extracellular matrix.

In mice, ES-derived megakaryocytes were formed after OP9 stromal cell co-cultures with thrombopoietin [81]. The proplatelets, which fragment into blood platelets, were developed from ES cells with integrin $\alpha \operatorname{IIb} \beta_{3}$-mediated signaling after OP9 stromal cell co-cultures followed by supplementation of thrombopoietin, IL-6 and IL-11 [82].

In humans, $\mathrm{CD} 41^{+}$megakaryocyte progenitors were generated after co-culturing the ES cells with S17 cells [78]. CD41 $\mathrm{a}^{+} / \mathrm{CD} 42 \mathrm{~b}^{+}$megakaryocyte lineage cells could 
be generated from human ES cells after co-cultures with OP9 stromal cells [83]. Platelets were induced from cell populations that expressed CD34, VE-cadherin, CD31, CD41a and CD45 surface antigen markers from both human ES cells and adult fibroblast-derived iPS cells after OP9 co-cultures [78].

\section{Variation of hematopoietic differentiation in embryonic stem/induced pluripotent stem cells}

In hematopoietic differentiation from mouse ES cells, CCE and D3 cell lines have been frequently used due to their high capability for hematopoietic differentiation, suggesting variation of hematopoietic potential among ES cell lines $[37,39,43]$. Previously, our group compared the differentiation potential of iPS cells derived from MEFs and adult somatic cells (hepatocytes and gastric epithelial cells). Among them, we found that MEFderived iPS cells were more efficient in generating Flk1expressing mesodermal cells and hematopoietic cells compared with adult-derived iPS cells [84]. In addition, we observed that each iPS cell line exhibits different mesodermal and hematopoietic potentials, although those iPS cell lines are derived from the same origin of tail tip fibroblasts [85]. Other groups also demonstrated that variation of mesodermal and hematopoietic potential is observed among mouse iPS cell lines depending on the origins of the cells $[39,86]$.

In humans, hematopoietic potential was examined in several ES and iPS cells. In vitro differentiation capabilities of myeloid and erythroid cells are not identical among human ES and iPS cells based on surface marker expression of CD45 (myeloid) and CD235 (erythroid) by flow cytometry $[45,87]$. Concerning the HPC potential, variation of HPC generation was observed based on CD34 expression by flow cytometry and in vitro colony formation by culture $[45,67]$. Taken together, such variation should be considered in hematopoietic differentiation for clinical purpose.

\section{Conclusion}

For clinical use of hematopoietic cells derived from ES/iPS cells, benefits and risks for patients should be considered. For transplantation and transfusion of hematopoietic cells, infections, rejection and donor risks have been addressed. Although ES/iPS technology potentially improves these issues, other problems such as cost of the products, efficiency of hematopoietic differentiation and quality of differentiated cells emerge as research progresses. Recently, the reprogramming capacity of hematopoietic cells at different stages of differentiation was compared, and HSCs/HPCs could be reprogrammed into iPS cells more frequently than mature lymphoid and myeloid cells [88]. Taken together with the variation of hematopoietic potential among iPS cells, it will be necessary to choose appropriate cells for reprogramming and to standardize the methods in iPS cell generation and differentiation for future regenerative medicine.

Note: This article is part of a thematic series on Stem cell research in the Asia-Pacific edited by Oscar Lee, Songtao Shi, Yufang Shi and Ying Jin. Other articles in the series can be found online at http://stemcellres.com/series/asiapacific.

\section{Abbreviations}

AGM: Aorta-gonad-mesonephros; CSF: Colony-stimulating factor; dpc: Days post coitum; EB: Embryoid body; Epo: Erythropoietin; ES: Embryonic stem; GFP: Green fluorescent protein; HPC: Hematopoietic progenitor cell; HSC: Hematopoietic stem cell; IL: Interleukin; iPS: Induced pluripotent stem; MEF: Mouse embryonic fibroblast; SCF: Stem cell factor; YS: Yolk sac.

\section{Competing interests}

The authors declare that they have no competing interests.

\section{Acknowledgements}

The authors are grateful for the grant support from the Ministry of Education, Culture, Sports, Science and Technology, the Ministry of Health, Labor and Welfare, the Japan Society for the Promotion of Science, and SENSHIN Medical Research Foundation, and thank Dr Kulkeaw for helpful discussion. Wai Feng Lim is the recipient of a fellowship supported by Takeda Scientific Foundation.

\section{Author details}

'Department of Advanced Medical Initiatives, Division of Hematopoietic Stem Cells, Advanced Medical Initiatives, Faculty of Medical Sciences, Kyushu University, Station for Collaborative Research 1, 4F, 3-1-1 Maidashi, Higashi-Ku, Fukuoka 812-8582, Japan. ${ }^{2}$ Department of Pathology, Faculty of Medicine and Health Sciences, Universiti Putra Malaysia, 43400 UPM, Serdang, Selangor Darul Ehsan, Malaysia. ${ }^{3}$ Department of Medicine and Biosystemic Science, Graduate School of Medical Sciences, Kyushu University, Fukuoka 812-8582, Japan.

Published: 18 June 2013

\section{References}

1. Dzierzak E, Speck NA: Of lineage and legacy: the development of mammalian hematopoietic stem cells. Nat Immunol 2008, 9:129-136.

2. Evans MJ, Kaufman MH: Establishment in culture of pluripotential cells from mouse embryos. Nature 1981, 292:154-156.

3. Thomson JA, Itskovitz-Eldor J, Shapiro SS, Waknitz MA, Swiergiel JJ, Marshall VS, Jones JM: Embryonic stem cell lines derived from human blastocysts. Science 1998, 282:1145-1147.

4. Doetschman TC, Eistetter H, Katz M, Schmidt W, Kemler R: The in vitro development of blastocyst-derived embryonic stem cell lines: formation of visceral yolk sac, blood islands and myocardium. J Embryol Exp Morphol 1985, 87:27-45.

5. Takahashi K, Yamanaka S: Induction of pluripotent stem cells from mouse embryonic and adult fibroblast cultures by defined factors. Cell 2006, 126:663-676

6. Gardner RL: Cell lineage and differentiation during growth of the early mammalian embryo. Proc Nutr Soc 1990, 49:269-279.

7. Palis J, Robertson S, Kennedy M, Wall C, Keller G: Development of erythroid and myeloid progenitors in the yolk sac and embryo proper of the mouse. Development 1999, 126:5073-5084.

8. Godin I, Dieterlen-Lievre F, Cumano A: Emergence of multipotent hemopoietic cells in the yolk sac and paraaortic splanchnopleura in mouse embryos, beginning at 8.5 days postcoitus. Proc Natl Acad Sci USA 1995, 92:773-777. 
9. Matsuoka S, Tsuji K, Hisakawa H, Xu M, Ebihara $Y$, Ishii T, Sugiyama D, Manabe A, Tanaka R, Ikeda Y, Asano S, Nakahata T: Generation of definitive hematopoietic stem cells from murine early yolk sac and paraaortic splanchnopleures by aorta-gonad-mesonephros region-derived stromal cells. Blood 2001, 98:6-12.

10. Yoder MC, Hiatt K, Dutt $P$, Mukherjee $P$, Bodine DM, Orlic D: Characterization of definitive lymphohematopoietic stem cells in the day 9 murine yolk sac. Immunity 1997, 7:335-344.

11. Medvinsky A, Dzierzak E: Definitive hematopoiesis is autonomously initiated by the AGM region. Cell 1996, 86:897-906.

12. Kumaravelu P, Hook L, Morrison AM, Ure J, Zhao S, Zuyev S, Ansell J, Medvinsky A: Quantitative developmental anatomy of definitive haematopoietic stem cells/long-term repopulating units (HSC/RUs): role of the aorta-gonad-mesonephros (AGM) region and the yolk sac in colonisation of the mouse embryonic liver. Development 2002 129:4891-4899.

13. Rhodes KE, Gekas C, Wang Y, Lux CT, Francis CS, Chan DN, Conway S, Orkin $\mathrm{SH}$, Yoder MC, Mikkola HK: The emergence of hematopoietic stem cells is initiated in the placental vasculature in the absence of circulation. Cell Stem Cell 2008, 2:252-263.

14. Samokhvalov IM, Samokhvalova NI, Nishikawa S: Cell tracing shows the contribution of the yolk sac to adult haematopoiesis. Nature 2007, 446:1056-1061.

15. Sugiyama D, Ogawa M, Nakao K, Osumi N, Nishikawa S, Arai K, Nakahata T, Tsuji K: B cell potential can be obtained from pre-circulatory yolk sac, but with low frequency. Dev Biol 2007, 301:53-61.

16. Sasaki T, Mizuochi C, Horio Y, Nakao K, Akashi K, Sugiyama D: Regulation of hematopoietic cell clusters in the placental niche through SCF/Kit signaling in embryonic mouse. Development 2010, 137:3941-3952.

17. Herrmann BG: Expression pattern of the Brachyury gene in whole-mount TWis/TWis mutant embryos. Development 1991, 113:913-917.

18. Shalaby F, Rossant J, Yamaguchi TP, Gertsenstein M, Wu XF, Breitman ML, Schuh AC: Failure of blood-island formation and vasculogenesis in Flk-1 -deficient mice. Nature 1995, 376:62-66.

19. Porcher C, Swat W, Rockwell K, Fujiwara Y, Alt FW, Orkin SH: The T cell leukemia oncoprotein SCL/tal-1 is essential for development of all hematopoietic lineages. Cell 1996, 86:47-57.

20. Lacaud G, Gore L, Kennedy M, Kouskoff V, Kingsley P, Hogan C, Carlsson L, Speck N, Palis J, Keller G: Runx1 is essential for hematopoietic commitment at the hemangioblast stage of development in vitro. Blood 2002, 100:458-466

21. Orkin SH: GATA-binding transcription factors in hematopoietic cells. Blood 1992, 80:575-581.

22. Ema M, Yokomizo T, Wakamatsu A, Terunuma T, Yamamoto M, Takahashi S: Primitive erythropoiesis from mesodermal precursors expressing VEcadherin, PECAM-1, Tie2, endoglin, and CD34 in the mouse embryo. Blood 2006, 108:4018-4024

23. Ferkowicz MJ, Starr M, Xie X, Li W, Johnson SA, Shelley WC, Morrison PR, Yoder MC: CD41 expression defines the onset of primitive and definitive hematopoiesis in the murine embryo. Development 2003, 130:4393-4403.

24. Sanchez MJ, Holmes A, Miles C, Dzierzak E: Characterization of the first definitive hematopoietic stem cells in the AGM and liver of the mouse embryo. Immunity 1996, 5:513-525.

25. Mizuochi C, Fraser ST, Biasch K, Horio Y, Kikushige Y, Tani K, Akashi K, Tavian $M$, Sugiyama D: Intra-aortic clusters undergo endothelial to hematopoietic phenotypic transition during early embryogenesis. PLOS One 2012, 7:e35763.

26. Schmitt RM, Bruyns E, Snodgrass HR: Hematopoietic development of embryonic stem cells in vitro: cytokine and receptor gene expression. Genes Dev 1991, 5:728-740.

27. Wiles MV, Keller G: Multiple hematopoietic lineages develop from embryonic stem (ES) cells in culture. Development 1991, 111:259-267.

28. Choi K, Kennedy M, Kazarov A, Papadimitriou JC, Keller G: A common precursor for hematopoietic and endothelial cells. Development 1998, 125:725-732.

29. Fehling HJ, Lacaud G, Kubo A, Kennedy M, Robertson S, Keller G, Kouskoff V: Tracking mesoderm induction and its specification to the hemangioblast during embryonic stem cell differentiation. Development 2003, 130:4217-4227.

30. Itskovitz-Eldor J, Schuldiner M, Karsenti D, Eden A, Yanuka O, Amit M, Soreq $\mathrm{H}$, Benvenisty N: Differentiation of human embryonic stem cells into embryoid bodies compromising the three embryonic germ layers. $\mathrm{Mol}$ Med 2000, 6:88-95.

31. Kennedy M, D'Souza SL, Lynch-Kattman M, Schwantz S, Keller G: Development of the hemangioblast defines the onset of hematopoiesis in human ES cell differentiation cultures. Blood 2007, 109:2679-2687.

32. Lengerke C, Grauer M, Niebuhr NI, Riedt T, Kanz L, Park IH, Daley GQ: Hematopoietic development from human induced pluripotent stem cells. Ann N Y Acad Sci 2009, 1176:219-227.

33. Ng ES, Davis RP, Azzola L, Stanley EG, Elefanty AG: Forced aggregation of defined numbers of human embryonic stem cells into embryoid bodies fosters robust, reproducible hematopoietic differentiation. Blood 2005 106:1601-1603.

34. Ye Z, Zhan H, Mali P, Dowey S, Williams DM, Jang YY, Dang CV, Spivak JL, Moliterno AR, Cheng L: Human-induced pluripotent stem cells from blood cells of healthy donors and patients with acquired blood disorders. Blood 2009, 114:5473-5480.

35. Yoshida H, Hayashi S, Kunisada T, Ogawa M, Nishikawa S, Okamura H, Sudo T, Shultz LD: The murine mutation osteopetrosis is in the coding region of the macrophage colony stimulating factor gene. Nature 1990, 345:442-444

36. Weisel KC, Gao Y, Shieh JH, Moore MA: Stromal cell lines from the aortagonado-mesonephros region are potent supporters of murine and human hematopoiesis. Exp Hematol 2006, 34:1505-1516.

37. Nakano T, Kodama H, Honjo T: Generation of lymphohematopoietic cells from embryonic stem cells in culture. Science 1994, 265:1098-1101.

38. Krassowska A, Gordon-Keylock S, Samuel K, Gilchrist D, Dzierzak E, Oostendorp R, Forrester LM, Ansell JD: Promotion of haematopoietic activity in embryonic stem cells by the aorta-gonad-mesonephros microenvironment. Exp Cell Res 2006, 312:3595-3603.

39. Niwa A, Umeda K, Chang H, Saito M, Okita K, Takahashi K, Nakagawa M, Yamanaka S, Nakahata T, Heike T: Orderly hematopoietic development of induced pluripotent stem cells via Flk-1(+) hemoangiogenic progenitors. J Cell Physiol 2009, 221:367-377

40. Choi KD, Yu J, Smuga-Otto K, Salvagiotto G, Rehrauer W, Vodyanik M, Thomson J, Slukvin I: Hematopoietic and endothelial differentiation of human induced pluripotent stem cells. Stem Cells 2009, 27:559-567.

41. Ma F, Ebihara Y, Umeda K, Sakai H, Hanada S, Zhang H, Zaike Y, Tsuchida E, Nakahata T, Nakauchi H, Tsuji K: Generation of functional erythrocytes from human embryonic stem cell-derived definitive hematopoiesis. Proc Natl Acad Sci USA 2008, 105:13087-13092.

42. Ledran MH, Krassowska A, Armstrong L, Dimmick I, Renstrom J, Lang R, Yung S, Santibanez-Coref M, Dzierzak E, Stojkovic M, Oostendorp RA, Forrester L, Lako M: Efficient hematopoietic differentiation of human embryonic stem cells on stromal cells derived from hematopoietic niches. Cell Stem Cell 2008, 3:85-98.

43. Nishikawa SI, Nishikawa S, Hirashima M, Matsuyoshi N, Kodama H: Progressive lineage analysis by cell sorting and culture identifies FLK1 ${ }^{+} \mathrm{VE}$-cadherin ${ }^{+}$cells at a diverging point of endothelial and hemopoietic lineages. Development 1998, 125:1747-1757.

44. Salvagiotto G, Burton S, Daigh CA, Rajesh D, Slukvin II, Seay NJ: A defined, feeder-free, serum-free system to generate in vitro hematopoietic progenitors and differentiated blood cells from hESCs and hiPSCs. PLoS One 2011, 6:e17829.

45. Niwa A, Heike T, Umeda K, Oshima K, Kato I, Sakai H, Suemori H, Nakahata T, Saito MK: A novel serum-free monolayer culture for orderly hematopoietic differentiation of human pluripotent cells via mesodermal progenitors. PLoS One 2011, 6:e22261.

46. Okada S, Nakauchi H, Nagayoshi K, Nishikawa S, Miura Y, Suda T: In vivo and in vitro stem cell function of c-kit- and Sca-1-positive murine hematopoietic cells. Blood 1992, 80:3044-3050.

47. Ogawa M, Matsuzaki Y, Nishikawa S, Hayashi S, Kunisada T, Sudo T, Kina T, Nakauchi H: Expression and function of c-kit in hemopoietic progenitor cells. J Exp Med 1991, 174:63-71.

48. Matsuoka S, Ebihara $Y, X u$ M, Ishii T, Sugiyama D, Yoshino $H$, Ueda $T$, Manabe A, Tanaka R, Ikeda Y, Nakahata T, Tsuji K: CD34 expression on long-term repopulating hematopoietic stem cells changes during developmental stages. Blood 2001, 97:419-425.

49. Iwama A, Hamaguchi I, Hashiyama M, Murayama Y, Yasunaga K, Suda T: Molecular cloning and characterization of mouse TIE and TEK receptor tyrosine kinase genes and their expression in hematopoietic stem cells. Biochem Biophys Res Commun 1993, 195:301-309. 
50. Satterthwaite AB, Burn TC, Le Beau MM, Tenen DG: Structure of the gene encoding CD34, a human hematopoietic stem cell antigen. Genomics 1992, 12:788-794.

51. Palacios R, Golunski E, Samaridis J: In vitro generation of hematopoietic stem cells from an embryonic stem cell line. Proc Natl Acad Sci USA 1995, 92:7530-7534.

52. Hole N, Graham GJ, Menzel U, Ansell JD: A limited temporal window for the derivation of multilineage repopulating hematopoietic progenitors during embryonal stem cell differentiation in vitro. Blood 1996, 88:1266-1276.

53. Burt RK, Verda L, Kim DA, Oyama Y, Luo K, Link C: Embryonic stem cells as an alternate marrow donor source: engraftment without graft-versus -host disease. J Exp Med 2004, 199:895-904.

54. Kyba M, Perlingeiro RC, Daley GQ: HoxB4 confers definitive lymphoidmyeloid engraftment potential on embryonic stem cell and yolk sac hematopoietic progenitors. Cell 2002, 109:29-37.

55. Wang Y, Yates F, Naveiras O, Ernst P, Daley GQ: Embryonic stem cell-derived hematopoietic stem cells. Proc Natl Acad Sci USA 2005, 102:19081-19086.

56. Matsumoto K, Isagawa T, Nishimura T, Ogaeri T, Eto K, Miyazaki S, Miyazaki J, Aburatani $\mathrm{H}$, Nakauchi $\mathrm{H}$, Ema H: Stepwise development of hematopoietic stem cells from embryonic stem cells. PLoS One 2009, 4:e4820

57. Zhang XB, Beard BC, Trobridge GD, Wood BL, Sale GE, Sud R, Humphries RK, Kiem HP: High incidence of leukemia in large animals after stem cell gene therapy with a HOXB4-expressing retroviral vector. J Clin Invest 2008, 118:1502-1510.

58. Tashiro K, Kawabata K, Omori M, Yamaguchi T, Sakurai F, Katayama K, Hayakawa T, Mizuguchi H: Promotion of hematopoietic differentiation from mouse induced pluripotent stem cells by transient HoxB4 transduction. Stem Cell Res 2012, 8:300-311.

59. Hanna J, Wernig M, Markoulaki S, Sun CW, Meissner A, Cassady JP, Beard C, Brambrink T, Wu LC, Townes TM, Jaenisch R: Treatment of sickle cell anemia mouse model with iPS cells generated from autologous skin. Science 2007, 318:1920-1923.

60. Wang L, Menendez P, Shojaei F, Li L, Mazurier F, Dick JE, Cerdan C, Levac K Bhatia M: Generation of hematopoietic repopulating cells from human embryonic stem cells independent of ectopic HOXB4 expression. $J$ Exp Med 2005, 201:1603-1614.

61. Ma F, Wang D, Hanada S, Ebihara Y, Kawasaki H, Zaike Y, Heike T, Nakahata T, Tsuji K: Novel method for efficient production of multipotential hematopoietic progenitors from human embryonic stem cells. Int $\mathrm{J}$ Hematol 2007, 85:371-379.

62. Ji J, Vijayaragavan K, Bosse M, Menendez P, Weisel K, Bhatia M: OP9 stroma augments survival of hematopoietic precursors and progenitors during hematopoietic differentiation from human embryonic stem cells. Stem Cells 2008, 26:2485-2495.

63. Keller G, Kennedy M, Papayannopoulou T, Wiles MV: Hematopoietic commitment during embryonic stem cell differentiation in culture. $\mathrm{Mol}$ Cell Biol 1993, 13:473-486.

64. Motoyama N, Kimura T, Takahashi T, Watanabe T, Nakano T: bcl-x prevents apoptotic cell death of both primitive and definitive erythrocytes at the end of maturation. J Exp Med 1999, 189:1691-1698.

65. Chang $\mathrm{KH}$, Nelson AM, Cao H, Wang L, Nakamoto B, Ware CB, Papayannopoulou T: Definitive-like erythroid cells derived from human embryonic stem cells coexpress high levels of embryonic and fetal globins with little or no adult globin. Blood 2006, 108:1515-1523.

66. Olivier EN, Qiu C, Velho M, Hirsch RE, Bouhassira EE: Large-scale production of embryonic red blood cells from human embryonic stem cells. Exp Hematol 2006, 34:1635-1642

67. Chang CJ, Mitra K, Koya M, Velho M, Desprat R, Lenz J, Bouhassira EE: Production of embryonic and fetal-like red blood cells from human induced pluripotent stem cells. PLoS One 2011, 6:e25761.

68. Lieber JG, Webb S, Suratt BT, Young SK, Johnson GL, Keller GM, Worthen GS: The in vitro production and characterization of neutrophils from embryonic stem cells. Blood 2004, 103:852-859.

69. Yokoyama Y, Suzuki T, Sakata-Yanagimoto M, Kumano K, Higashi K Takato T, Kurokawa M, Ogawa S, Chiba S: Derivation of functional mature neutrophils from human embryonic stem cells. Blood 2009 113:6584-6592.

70. Zou J, Sweeney CL, Chou BK, Choi U, Pan J, Wang H, Dowey SN, Cheng L, Malech HL: Oxidase-deficient neutrophils from X-linked chronic granulomatous disease iPS cells: functional correction by zinc finger nuclease-mediated safe harbor targeting. Blood 2011, 117:5561-5572.
71. Schmitt TM, de Pooter RF, Gronski MA, Cho SK, Ohashi PS, Zuniga-Pflucker JC: Induction of T cell development and establishment of T cell competence from embryonic stem cells differentiated in vitro. Nat Immunol 2004, 5:410-417.

72. Wada H, Kojo S, Kusama C, Okamoto N, Sato Y, Ishizuka B, Seino K: Successful differentiation to T cells, but unsuccessful B-cell generation, from B-cell-derived induced pluripotent stem cells. Int Immuno/ 2011, 23:65-74.

73. Lian RH, Maeda M, Lohwasser S, Delcommenne M, Nakano T, Vance RE, Raulet DH, Takei F: Orderly and nonstochastic acquisition of CD94/NKG2 receptors by developing NK cells derived from embryonic stem cells in vitro. J Immunol 2002, 168:4980-4987.

74. Timmermans F, Velghe I, Vanwalleghem L, De Smedt M, Van Coppernolle S, Taghon T, Moore HD, Leclercq G, Langerak AW, Kerre T, Plum J, Vandekerckhove B: Generation of T cells from human embryonic stem cell-derived hematopoietic zones. J Immunol 2009, 182:6879-6888.

75. Carpenter L, Malladi R, Yang CT, French A, Pilkington KJ, Forsey RW, Sloane-Stanley J, Silk KM, Davies TJ, Fairchild PJ, Enver T, Watt SM: Human induced pluripotent stem cells are capable of B-cell lymphopoiesis. Blood 2011, 117:4008-4011.

76. Ni Z, Knorr DA, Clouser CL, Hexum MK, Southern P, Mansky LM, Park IH, Kaufman DS: Human pluripotent stem cells produce natural killer cells that mediate anti-HIV-1 activity by utilizing diverse cellular mechanisms. J Virol 2011, 85:43-50.

77. Senju S, Haruta M, Matsunaga Y, Fukushima S, Ikeda T, Takahashi K, Okita K, Yamanaka S, Nishimura Y: Characterization of dendritic cells and macrophages generated by directed differentiation from mouse induced pluripotent stem cells. Stem Cells 2009, 27:1021-1031.

78. Kaufman DS, Hanson ET, Lewis RL, Auerbach R, Thomson JA: Hematopoietic colony-forming cells derived from human embryonic stem cells. Proc Natl Acad Sci USA 2001, 98:10716-10721.

79. Karlsson KR, Cowley S, Martinez FO, Shaw M, Minger SL, James W: Homogeneous monocytes and macrophages from human embryonic stem cells following coculture-free differentiation in M-CSF and IL-3. Exp Hematol 2008, 36:1167-1175.

80. Grigoriadis AE, Kennedy M, Bozec A, Brunton F, Stenbeck G, Park IH, Wagner EF, Keller GM: Directed differentiation of hematopoietic precursors and functional osteoclasts from human ES and iPS cells. Blood 2010, 115:2769-2776.

81. Era T, Takagi T, Takahashi T, Bories JC, Nakano T: Characterization of hematopoietic lineage-specific gene expression by ES cell in vitro differentiation induction system. Blood 2000, 95:870-878.

82. Eto K, Murphy R, Kerrigan SW, Bertoni A, Stuhlmann H, Nakano T, Leavitt AD, Shattil SJ: Megakaryocytes derived from embryonic stem cells implicate CaIDAG-GEFI in integrin signaling. Proc Natl Acad Sci USA 2002, 99:12819-12824.

83. Gaur M, Kamata T, Wang S, Moran B, Shattil SJ, Leavitt AD: Megakaryocytes derived from human embryonic stem cells: a genetically tractable system to study megakaryocytopoiesis and integrin function. J Thromb Haemost 2006, 4:436-442.

84. Kulkeaw K, Horio Y, Mizuochi C, Ogawa M, Sugiyama D: Variation in hematopoietic potential of induced pluripotent stem cell lines. Stem Cell Rev 2010, 6:381-389.

85. Inoue T, Kulkeaw K, Okayama S, Tani K, Sugiyama D: Variation in mesodermal and hematopoietic potential of adult skin-derived induced pluripotent stem cell lines in mice. Stem Cell Rev 2011, 7:958-968.

86. Reimer A, Seiler K, Tornack J, Tsuneto M, Melchers F: Reprogramming to iPS cells and their subsequent hematopoietic differentiation is more efficient from MEFs than from preB cells. Immunol Lett 2012, 143:70-76.

87. Maclean GA, Menne TF, Guo G, Sanchez DJ, Park IH, Daley GQ, Orkin SH: Altered hematopoiesis in trisomy 21 as revealed through in vitro differentiation of isogenic human pluripotent cells. Proc Natl Acad Sci USA 2012, 109:17567-17572.

88. Eminli S, Foudi A, Stadtfeld M, Maherali N, Ahfeldt T, Mostoslavsky G, Hock $H$, Hochedlinger K: Differentiation stage determines potential of hematopoietic cells for reprogramming into induced pluripotent stem cells. Nat Genet 2009, 41:968-976.

\section{doi:10.1186/scrt222}

Cite this article as: Lim et al:: Hematopoietic cell differentiation from embryonic and induced pluripotent stem cells. Stem Cell Research \& Therapy 2013 4:71. 